\title{
Precision Continuous Renal Replacement Therapy and Solute Control
}

\author{
Sean M. Bagshaw ${ }^{\mathrm{a}}$ Madarasu Rajasekara Chakravarthi ${ }^{\mathrm{b}}$ Zaccaria Ricci $^{\mathrm{e}}$ \\ Ashita Tolwani $^{d} \quad$ M. Neri $^{f}$ S. De Rosa ${ }^{f} \quad$ John A. Kellum ${ }^{c}$ \\ Claudio Ronco ${ }^{c, f, g}$ on behalf of the ADQI Consensus Group
}

${ }^{a}$ Critical Care Medicine, Faculty of Medicine and Dentistry, University of Alberta, Edmonton, Alta., Canada;

${ }^{b}$ Department of Nephrology, Star Hospitals, Hyderabad, India; ' ${ }^{\circ}$ Department of Critical Care Medicine, Center for Critical Care Nephrology, University of Pittsburgh School of Medicine, Pittsburgh, Pa., and d Division of Nephrology,

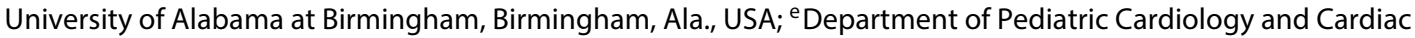
Surgery, Ospedale Pediatrico Bambino Gesù, IRCCS, Rome, ${ }^{f}$ International Renal Research Institute of Vicenza (IRRIV), and ${ }^{9}$ Department of Nephrology, Dialysis and Transplantation, San Bortolo Hospital, Vicenza, Italy

\section{Key Words}

Continuous renal replacement therapy - Precision CRRT .

Solute control · CRRT dose · Adequacy of CRRT · Acute

kidney injury · Dose · Intensity · Outcome · Quality

\begin{abstract}
Continuous renal replacement therapy (CRRT) remains the dominant form of renal support among critically ill patients worldwide. Current clinical practice on CRRT prescription mostly relies on high quality studies suggesting no impact of CRRT dose on critically ill patients' outcomes. Recent clin-
\end{abstract}

Brotzu', Cagliari, Italy; Osterman M., Guy's and St. Thomas' Hospital, London, UK; Ricci Z., Department of Pediatric Cardiology and Cardiac Surgery, Ospedale Pediatrico Bambino Gesù IRCCS, Roma, Italy; Rosner M., Department of Medicine, University of Virginia, Charlottesville, Va., USA; Samoni S., Institute of Life Sciences, Sant'Anna School of Advanced Studies, Pisa, Italy; Tolwani A.J., Department of Nephrology, University of Alabama at Birmingham, USA; Xiaoqiang Ding, Department of Nephrology, Shanghai Institute of Kidney and Dialysis, Zhongshan Hospital, Fudan University, Shanghai, China; Wuhua Jiang, Department of Nephrology, Shanghai Institute of Kidney and Dialysis, Zhongshan Hospital, Fudan University, Shanghai, China.

Report from the 17th Acute Disease Quality Initiative (ADQI) Consensus Conference. Asiago, Italy, June 10-13, 2016.

\section{KARGER}

E-Mail karger@karger.com

www.karger.com/bpu (c) 2016 S. Karger AG, Basel

$0253-5068 / 16 / 0423-0238 \$ 39.50 / 0$
Dr. Sean M. Bagshaw

Critical Care Medicine

Faculty of Medicine and Dentistry, University of Alberta

2-124E Clinical Sciences Building, 8440-122 Street, Edmonton, AB T6G2B7 (Canada)

E-Mail bagshaw@ualberta.ca 
ical practice guidelines have been developed based on these studies recommending a static prescribed CRRT dose of 20$25 \mathrm{ml} / \mathrm{kg} / \mathrm{h}$. There is a rationale for renewed attention to CRRT prescription/practice based on the concept of dynamic solute control adapted to the changing clinical needs of critically ill patients. In response, Acute Disease Quality Initiative convened a 17 th consensus meeting centered on reevaluation of CRRT. This work group developed 4 themes focused specifically on CRRT dose prescription, delivery and solute control that were summarized in a series of consensus statements, along with the identification of critical knowledge gaps. CRRT dose prescription and delivery can be based on effluent flow rate. Delivered dose should be routinely monitored to ensure coherence with prescribed dose. CRRT dose should be dynamic, in recognition of between- and within-patient variation in targeted solute control or unintended solute clearance. Quality measures specific for monitoring delivered CRRT dose have been proposed that require further validation, prior to implementation, into the practice of guiding optimal CRRT dosage.

(C) 2016 S. Karger AG, Basel

\section{Introduction}

Continuous renal replacement therapy (CRRT) dose delivery has conventionally been based on the clearance of urea as a surrogate for low molecular weight uremic toxins [1]. Since small solute clearance is approximately equal to CRRT effluent flow, the dose of CRRT is expressed as the effluent volume per unit of time, normalized to body weight [2]. Solute control was a key priority identified during the first Acute Disease Quality Initiative (ADQI) consensus meeting that focused exclusive on CRRT [3].

In the 16 years, since the first ADQI meeting, new evidence has emerged to address the issue of optimal CRRT dose, modality and methods for monitoring [4]. In particular, one of the recommendations for future research during the first ADQI meeting was to define a minimum dose of CRRT in the management of critically ill patients with severe acute kidney injury (AKI) $[1,5]$. Two highquality multicenter randomized trials focused on defining the association of delivered renal replacement therapy (RRT) dose and outcome in critically ill patients have been published $[6,7]$. The findings of these 2 landmark trials have informed key content in recent clinical practice guidelines (CPG) for the dose prescription and delivery of CRRT in the management of AKI [4].

Greater CRRT dose has not been shown to definitively improve survival or kidney recovery among critically ill patients with AKI [5-7]. However, these findings do not preclude that CRRT dose is not important. Moreover, nearly all these clinical trials of CRRT dose evaluated only fixed dose prescriptions. It remains uncertain whether a fixed or static dose is appropriate for critically ill patients whose clinical course may change unpredictably. The concept of 'precision medicine' could conceivably be applied to CRRT care in critically ill patients. The dynamic prescription of CRRT dose in response to the clinical, physiological and metabolic needs of the patient may translate into better quality of care and improved outcomes. Moreover, dynamic CRRT prescription would provide the opportunity to rigorously evaluate the implementation of evidence-based quality measures to guide CRRT care matched with the clinical course of the critically ill patient.

\section{Methods}

The methodology of ADQI consensus meetings are well developed and have undergone refinement in the last 2 decades, as previously described [8]. The aim of ADQI is to provide expert-based statements, supported by evidence where applicable, and interpretation of current knowledge for use in clinical care by healthcare providers and decision-makers. In addition, ADQI aims to identify evidence care gaps to further establish research priorities. The 17th ADQI consensus meeting convened a diverse panel of experts representing the disciplines of nephrology, critical care, epidemiology, biostatistics and biomedical engineering around the theme of 'Continuous Renal Replacement Therapy' for a 3-day meeting in Asiago, Italy (June 10-13, 2016) [3].

The ADQI methodology begins with a pre-conference comprehensive literature search and appraisal of scientific evidence to identify key themes. The core theme for this work group centered on 'solute control in CRRT'. The work group summarized areas where there is consensus supported by evidence, consensus but limited or no evidence and existing knowledge gaps where consensus was uncertain. The work group identified 4 core themes to generate questions on for presentation to the ADQI delegates during the meeting (table 1). The work group iteratively developed and refined consensus statements in response to each core question. Core questions and statements were presented during 5 successive plenary sessions involving all ADQI delegates for debate, discussion, suggested revisions and final consensus. Following the conference, this summary review of the process and final content was generated, reviewed and approved by all work group members.

\section{Review}

Question 1: What is the ideal method to prescribe and measure delivered CRRT dose for solute control? 


\section{Consensus Statements} Prescription

(1) CRRT dose identifies the amount of blood cleared of solute by unit of time (Level III; Grade D).

(2) Effluent flow is an acceptable surrogate for prescribing CRRT dose for solute clearance. The clearance is dependent on the sieving coefficient of the representative solute (Level III; Grade D).

(3) Default prescribed CRRT dose should be $20-25 \mathrm{ml} /$ $\mathrm{kg} / \mathrm{h}$ for representative small molecular weight solutes. Urea is the solute most commonly used to quantify dose (Level III; Grade D).

(4) Prescribed dose is dynamic. This default prescribed dose can be modified according to patient demand and in response to iterative evaluation of quality measures. Prescribed dose should be evaluated at least once every $24 \mathrm{~h}$ and more often according to patient needs (Level V; Grade E).

\section{Delivery}

(5) Dose delivery can be estimated as intensity $(\mathrm{ml} / \mathrm{kg} / \mathrm{h}$ times the number of treatment hours) or as time-averaged (average $\mathrm{ml} / \mathrm{kg} / \mathrm{h}$ over $24 \mathrm{~h}$ or other duration) (Level III; Grade D).

(6) Dose delivery should be routinely reassessed and modified based on iterative evaluation of quality measures. Dose delivery should be evaluated at least once every $24 \mathrm{~h}$ often according to patient needs (Level V; Grade E).

\section{Context}

CRRT dose is most commonly defined by extracorporeal urea clearance [1]. Urea clearance (sieving coefficient $\sim 1$ ) is reasonably estimated by weight-based effluent flow rate $(\mathrm{ml} / \mathrm{kg} / \mathrm{h})$ [9]. Urea is most commonly used as a surrogate for clearance of small solutes; however, it is not the only solute readily removed by CRRT. Extracorporeal solute clearance is dependent on solute molecular weight, sieving coefficient, membrane type and fouling and modality [10]. Conventional CRRT membranes efficiently remove small solutes. Larger molecules are better cleared with hemofiltration and in the first $12 \mathrm{~h}$ of filter use [11]. Small molecular weight solutes are not significantly affected by CRRT modality or progressive clotting of the membrane [11].

The Kidney Disease: Improving Global Outcome (KDIGO) CPG for AKI have recommended a default CRRT dose prescription (for urea clearance) of 20-25 ml/ $\mathrm{kg} / \mathrm{h}$ effluent flow rate, regardless the chosen modality or proportion of replacement fluid given pre or post filter [4, 12]. Recent data have shown that CRRT dose lower than recommended by the KDIGO CPG default dose can achieve adequate control of serum urea concentrations [13]. This study implies that providers can adjust or adapt the default CRRT dose based on the patient's clinical condition and need. Effluent flow rate can be increased or decreased in response to changes in clinical, physiologic and/or metabolic status. This may include targeting specific solutes and/or modification in response achieving benchmark targets from CRRT quality measures. Importantly, there are currently no data to support the concept that dynamic prescription improves surrogate or patientcentered outcomes. However, the rationale for dynamic prescription integrating audit and feedback from routine quality measures could theoretically better optimize solute control and quality of delivered CRRT [14].

We contend that CRRT dose delivery should be routinely monitored. Intensity may be a reasonable method to measure delivered dose [2]. Intensity is defined by the product of efficiency and time, where efficiency is the clearance measured in milliliters per kilogram per hour. Intensity represents the blood volume cleared of a solute after a certain period of time and can be expressed as milliliters or milliliters per kilogram. For example, prescribing $20 \mathrm{ml} / \mathrm{kg} / \mathrm{h}$ to a $100 \mathrm{~kg}$ patient after $24 \mathrm{~h}$ of uninterrupted therapy should result in $480 \mathrm{ml} / \mathrm{kg}$ of intensity (or 48 liters in a $100 \mathrm{~kg}$ patient). If the actual result is less than $480 \mathrm{ml} /$ $\mathrm{kg}$ of intensity due to treatment interruption or downtime, the effective delivered dose is less than the prescribed dose.

Alternatively, delivered dose can be calculated as timeaveraged dose in milliliters per kilogram per hour over the 24-hour timeframe. For example, if a prescription of $20 \mathrm{ml} / \mathrm{kg} / \mathrm{h}$ is applied for $12 \mathrm{~h}$, then decreased to $15 \mathrm{ml} /$ $\mathrm{kg} / \mathrm{h}$ over the subsequent $6 \mathrm{~h}$ and interrupted thereafter (the next $6 \mathrm{~h}$ ), the time-averaged dose will be the following: $((20 \times 12)+(15 \times 6)+(0 \times 6)) / 24=13.75 \mathrm{ml} / \mathrm{kg} / \mathrm{h}$. This would represent a delivered dose below that of the intended level. This would represent suboptimal CRRT care. Effective delivered dose should be monitored routinely to ensure the prescribed CRRT is achieved [15] (fig. 1).

We recognize that CRRT dose is only one dimension of 'CRRT adequacy'. Accordingly, additional aspects of CRRT care should also be integrated and monitored in the broader clinical context of the patient's clinical status (i.e., timing, fluid removal, anticoagulation) [13].

\section{Recommendations for Clinical Practice}

A reference dose of $20-25 \mathrm{ml} / \mathrm{kg} / \mathrm{h}$ can be reasonably recommended as the default prescription for CRRT dose in critically ill patients. This dose represents small mo- 


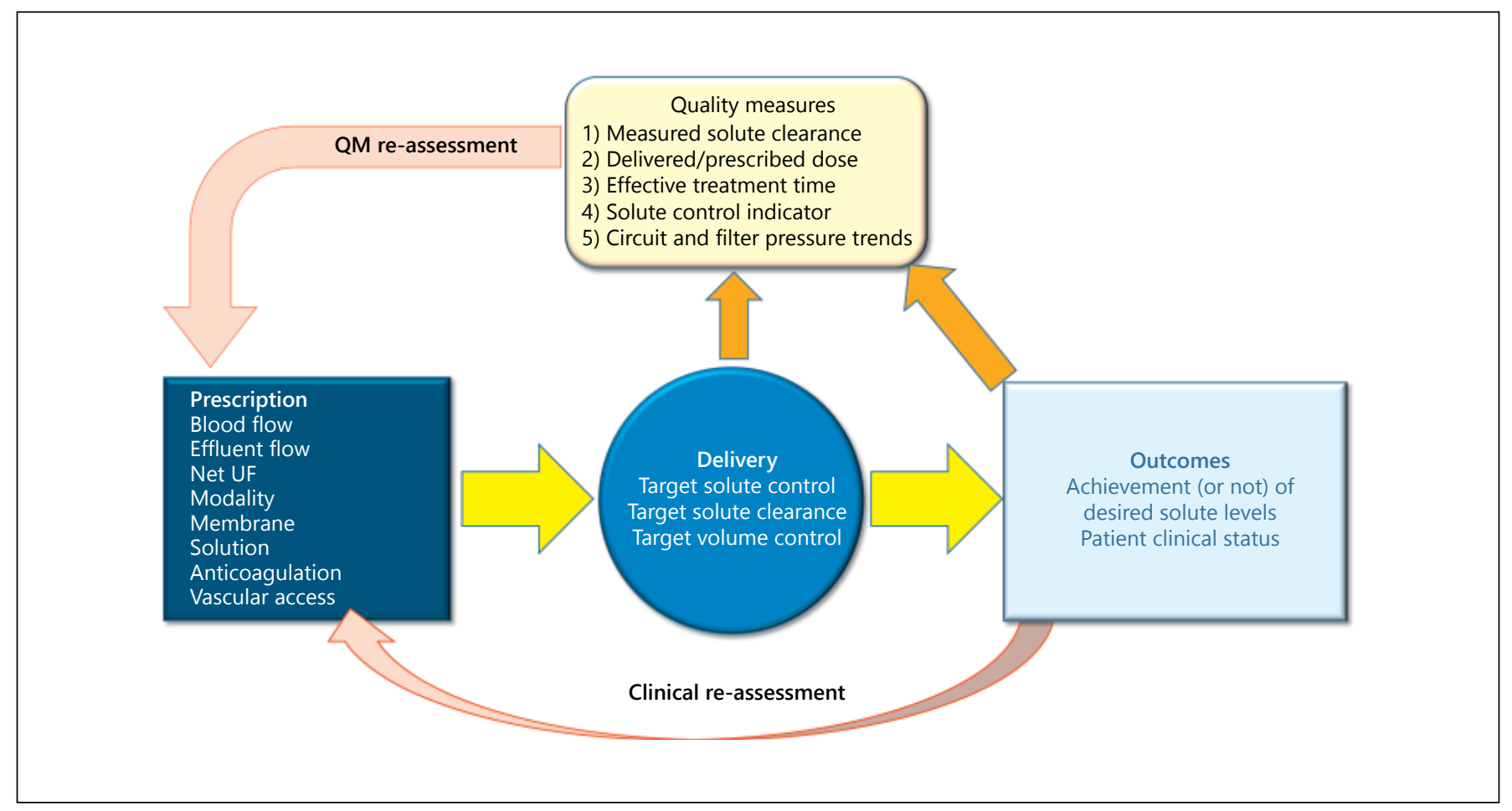

Fig. 1. Concept of dynamic CRRT dose. Following the initial prescription of CRRT, treatment begins which may modify patient course and outcome. At this point, providers should frequently reassess the response to prescribed CRRT dose. This can be achieved by following selected quality measures focused on CRRT dose. These quality measures could target delivered clearance; ratio of delivered to prescribed dose; effective treatment time; and

lecular weight solute clearance (e.g., urea) and should be modified according to the changing status of the patient. A critically important aspect to monitor for CRRT prescription is delivered dose. This should be monitored as a quality measure.

\section{Recommendations for Research}

We identified the following themes for future research:

- Future work should identify specific and/or novel target solutes for CRRT prescription and blood level control (e.g., middle molecular weight solutes, biomarkers etc.) [16].

- Future work should identify the optimal technique (indicated as the combination of membrane/modality/ efficiency) in order to target specific solutes.

- Future work should identify the optimal timeframe for routine prescription re-evaluation.

- Future work should identify the optimal timeframe for routine intensity assessment. other measures of solute control. Furthermore, the patient's clinical condition may change while receiving CRRT. In such circumstances, CRRT prescription may require additional modification (e.g., reduction or interruption of net ultrafiltration in response to hemodynamic deterioration and/or hypovolemia). Reprinted with permission from www.ADQI.org.

Question 2: What are the effects of the delivered dose of CRRT on solute control?

\section{Consensus Statements}

(1) Delivered dose of CRRT is dynamic and affects the clearance of urea and other solutes. Clearance of such solutes may or may not be intended as part of the CRRT prescription. Examples of solutes initially targeted for removal include creatinine, potassium, phosphate, sodium, uric acid and ammonia (Level I; Grade A).

(2) Unintended removal of solutes can lead to potential adverse effects. Examples include excessive clearance of phosphate, potassium, magnesium, nutrients and medications (i.e., antimicrobials) (Level II; Grade B).

(3) Delivered CRRT dose affects the acid-base balance (Level I; Grade A).

(4) Solute clearance is further contingent on technological factors such as CRRT modality, membrane characteristics and CRRT operational characteristics (Level II; Grade B). 


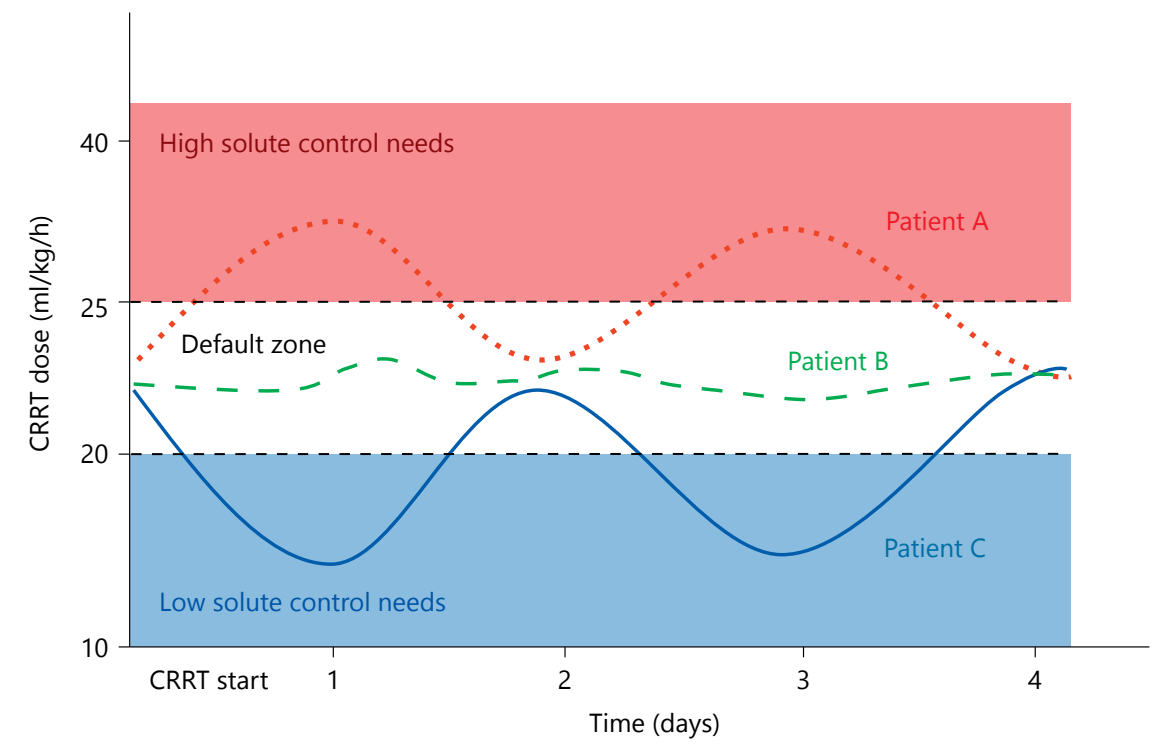

Fig. 2. Precision CRRT delivery. CRRT dose should be dynamic and adapted to changes in acuity, physiology and metabolic profile of critically ill patients. For example, patient A has pneumonia and oliguric AKI. The CRRT dose is increased from the default of $20-35 \mathrm{ml} / \mathrm{kg} / \mathrm{h}$ after $24 \mathrm{~h}$ due to the development of a hypercatabolic state characterized by sepsis and increasing serum urea concentration. The next day, the patient's condition improves and urea control is achieved. The CRRT dose can now be reverted to $20 \mathrm{ml} /$ $\mathrm{kg} / \mathrm{h}$. By day 3 , the patient receives nutritional support which contributes to increasing serum urea concentrations at a CRRT dose of $20 \mathrm{ml} / \mathrm{kg} / \mathrm{h}$. This would again require dose modification. Alterna-

\section{Context}

The clearance of low molecular weight solutes during CRRT closely approximates total effluent flow. An effluent volume of $20-25 \mathrm{ml} / \mathrm{kg} / \mathrm{h}$ is recognized as an accepted dose of CRRT in critically ill patients with AKI and represents urea clearance $[4,6,7]$. The prescription and delivery of CRRT dose affects other aspects of medical management, including correction of electrolyte and acidbase imbalance, volume control and clearance of other solutes and medications. Clearance of solutes such as creatinine, potassium, phosphate, sodium, uric acid and ammonia may be initially indicated based on the desired target level for the solute. However, a higher dose than 20-25 $\mathrm{ml} / \mathrm{kg} / \mathrm{h}$ may be indicated if the target level of a specific solute cannot be achieved. Similarly, a higher dose of CRRT may be required to maintain the acid-base homeostasis or to correct evolving acid-base disturbances. While the default initial CRRT dose recommendation of $20-25 \mathrm{ml} / \mathrm{kg} / \mathrm{h}$ applies to the majority of critically ill patients, the CRRT prescription may need individualization tively, patient $\mathrm{C}$ has diuretic-resistant congestive heart failure and fluid overload. Following initial CRRT prescription primarily for fluid removal, solute clearance exceeds demand due to residual kidney function. Accordingly, the patient's CRRT dose is reduced to $15 \mathrm{ml} / \mathrm{kg} / \mathrm{h}$. By day 2, the patient's urine output decreases and serum urea concentration increases. In this circumstance, the prescribed CRRT dose can be increased to achieve the new solute control target. Finally, patient B is critically ill and is admitted to ICU following surgery. This patient achieves steady state solute control without the need for modification with the default CRRT dose of $20-25 \mathrm{ml} / \mathrm{kg} / \mathrm{h}$. Reprinted with permission from www.ADQI.org.

and iterative reassessment with appropriate adjustments to achieve adequate fluid, electrolyte and metabolic balance (fig. 2).

CRRT delivered dose can also result in the clearance of unintended solutes, potentially contributing adverse events. CRRT can cause significant electrolyte derangements due to removal of solute from the blood without adequate replacement $[17,18]$. Both hypophosphatemia and hypokalemia frequently complicate prolonged treatment. While initial phosphate removal may be indicated to achieve a biochemical target, continued removal can result in hypophosphatemia [6, 7, 19, 20]. Hypophosphatemia has been associated with respiratory muscle weakness, delayed ventilator weaning, myocardial dysfunction and rhabdomyolysis, as well as with other complications. Analogously, initial potassium removal may be indicated but continued removal can predispose to hypokalemia and cardiac dysrhythmias.

CRRT dose may also impact nutritional parameters and vital medication dosing. Since the CRRT readily 
clears low molecular weight water-soluble substances, significant loss of glucose, amino acids, low molecular weight proteins, vitamins and trace elements also occur $[21,22]$. CRRT delivered dose also has the inadvertent consequence of increasing drug clearances and can result in the potential suboptimal dosing of antimicrobials [23, 24]. Therefore, the influence of CRRT dose must be taken into account when prescribing antimicrobials and other vital medications. CRRT modality, CRRT operational characteristics and membrane characteristics can affect the dose $[2,25,26]$. The clearance of 'middle' molecular weight solutes is greater for convective than diffusionbased techniques [27]. In convective therapies, the location of replacement fluid delivery in the extracorporeal circuit significantly impacts solute clearance. Replacement fluid can be infused prior to the filter (pre-filter) or after the filter (post-filter) in varying amounts. The use of post-filter [28] replacement fluid is limited by the filtration fraction due to increased clotting of the CRRT circuit. While addition of the replacement fluid pre filter can reduce the filtration fraction and likelihood of filter clotting, it also decreases solute clearance $[12,28]$. High-flux, high cutoff and adsorptive membranes can increase removal of both middle and large molecular weight solutes [29].

\section{Recommendations for Clinical Practice}

In prescribing CRRT dose, additional parameters should be considered beyond urea clearance, such as acid-base and electrolyte homeostasis, nutrition, fluid balance and antimicrobial clearance. Monitoring of serum concentrations of target solutes, along with complications of delivered dose, should routinely be performed at least once every $24 \mathrm{~h}$ or more frequently based on patient need. CRRT prescription may require adjustment to achieve the physiologic target of these other solutes. At the same time, excessive clearance of electrolytes and other solutes such as nutrients may need to be supplemented. Patients on CRRT should have consultation with a critical care dietician to prescribe suitable nutritional support and a critical care pharmacist to perform dose adjustment of medications. Therapeutic drug monitoring should also be used when possible to ensure more accurate antibiotic therapy.

\section{Recommendations for Research}

We identified the following themes for future research:

- Future research should include the evaluation of other aspects of delivered CRRT dose including fluid management and acid-base and electrolyte balance.
- Future research should include assessment of the impact of non-CRRT fluids and solute administered on delivered dose.

- Rigorous evaluation of the appropriate dosing of antibiotics based on pharmacokinetic studies is needed since data are limited.

- Future research should include assessment of nutritional losses and the impact of supplementation on patient outcomes.

Question 3: Can precision modification of target CRRT dose tailored to evolving patient status contribute to improved patient outcome?

\section{Consensus Statements}

(1) CRRT dose should be dynamic and adapted to changes occurring in the acuity, physiology and metabolic profile of the critically ill patient. Critically ill patients are heterogeneous and vary widely in their demographics, chronic disease burden, case-mix and illness acuity (Level V; Grade E).

(2) Precision CRRT dosing should be adapted to target specific solutes (Level V; Grade E).

\section{Context}

We recognize that critically ill patients are a heterogeneous mix characterized by wide differences susceptibilities to AKI, its complications and outcome (e.g., metabolic derangement, acidosis, fluid overload) [30-32]. Critically ill patients vary in age, body weight and composition, burden of comorbid disease (in particular chronic kidney disease), case-mix and acute illness severity. Accordingly, a standard and fixed CRRT dose of 20$25 \mathrm{ml} / \mathrm{kg} / \mathrm{h}$ may not be appropriate for critically ill patients whose course of critical illness may be marked by rapid changes in clinical, physiological and metabolic profile. While we believe current evidence would recommend a default CRRT dose of $20-25 \mathrm{ml} / \mathrm{kg} / \mathrm{h}$, we recognize that the prescription of CRRT may need to be dynamic. This introduces the concept of a patient-centered 'precision' approach to CRRT prescription. This would imply that CRRT dose would be modified over time to match the clinical demands of the patient (i.e., changes to kidney reserve, changes to illness severity, changes to non-renal organ dysfunction, changes to fluid balance and metabolic status) [33]. This would be analogous to how mechanical ventilation is prescribed in critically ill patients with acute lung injury.

For example, a hypercatabolic critically ill patient (e.g., burn injury or tumor lysis syndrome) may initially require 
a greater CRRT dose than the default of $20-25 \mathrm{ml} / \mathrm{kg} / \mathrm{h}$ to achieve acceptable solute control (i.e., azotemia and electrolyte derangement). As the patient's clinical status improves, the CRRT dose should naturally be reduced to 20 $25 \mathrm{ml} / \mathrm{kg} / \mathrm{h}$. This default CRRT dose could be further decreased in a patient who starts to recovery kidney function characterized by increasing residual kidney function. An alternative example would be a critically ill patient with sufficient residual kidney function to maintain reasonable solute control, however requires CRRT for management of fluid overload. Such patients may not initially require the default CRRT dose of $20-25 \mathrm{ml} / \mathrm{kg} / \mathrm{h}$ for solute unless they suffer further deterioration in kidney function.

We also recognize that CRRT dose may necessitate targeting of specific solutes relevant to the baseline and changing clinical status of the patient. For example, a critically ill patient with rhabdomyolysis may demand a greater CRRT dose, using convective therapies and a high cutoff membrane to clear high circulating concentrations of myoglobin. Similarly, critically ill patients who initialed achieved stable state solute control with the default CRRT dose of 20-25 ml $/ \mathrm{kg} / \mathrm{h}$ may suffer further deterioration marked by severe acidemia [34]. The prescribed CRRT dose would then need to be modified to control of acidosis.

\section{Recommendations for Clinical Practice}

Providers should recognize that the prescription of CRRT dose is dynamic and may need to be modified in response to patient factors such as baseline susceptibilities and reserve and changes in clinical status. Accordingly, CRRT dose should be customized and tailored to the specific demands of the individual patient.

\section{Recommendations for Research}

We identified the following themes for future research:

- Future work should integrate the changes in residual kidney function of patients receiving CRRT to guide optimal dose.

- Future work should evaluate candidate biomarkers and actionable levels of biomarkers to guide when to start CRRT and also when to potentially modify dose during the course of treatment.

- Future work should evaluate subgroups of critically ill patients where precision CRRT dose modifications may improve patient-centered outcomes such as survival and recovery of kidney function.

Question 4: What quality measures (quality indicators) should monitor dose and solute control in CRRT?

\section{Consensus Statements}

(1) Quality measures for CRRT should be implemented into the routine clinical application of CRRT (Level V; Grade E).

(2) Quality measures should specifically target CRRT dose prescription, delivery and solute control (Level V; Grade E).

(3) CRRT technology and bedside electronic health records (EHRs) should be leveraged to reliably and routinely calculate quality measures (Level V; Grade E).

(4) Quality measures, specifically benchmark targets, should be reported at both patient level and, in aggregate, at an operational level (Level V; Grade E).

\section{Context}

The quality of care for critically ill patients receiving CRRT has been recognized as a clinical and research priority [14]. Indeed, several organizations (i.e., ADQI, KDIGOs) have worked towards implementing evidencebased guidelines for CRRT care, improving the standards of care for patients receiving CRRT and identifying important knowledge gaps [35-37]. Despite these initiatives, there remain numerous challenges with respect to quality and safety in CRRT care.

CRRT is the predominant form of acute RRT provided to critically ill patients and its utilization is increasing [38]. CRRT is a therapeutic and support technology often applied to the most severely ill patients, often in the context of multiple organ dysfunction, and among those who are particularly prone to medical errors and adverse events [14]. CRRT is also relatively resource intensive, costly and requires specialized training to operate.

CRRT is also susceptible to considerable variation in practice. Such practice variation may contribute to independent risk for suboptimal quality of care and/or less favorable outcomes $[15,26,39]$. Such variation is likely multifactorial and has arisen from critical evidence care gaps to guide practice, heterogeneous providers (e.g., nephrology; critical) and differences in institutional expertise in CRRT. We also recognize there is a paucity of validated evidence-informed quality measures available to implement into routine practice to guide and monitor aspects of CRRT prescription and delivery $[14,15,26,39$, 40]. This is a clear clinical and research priority.

The aim of integrating quality measures into routine clinical CRRT care is to standardize a default prescription, ensure greater reliability of CRRT delivery and target aspects for continuous quality improvement initiatives. We recognize that quality measures should be developed across a range of domains related to CRRT care 
Table 1. Summary of core questions focused on 'solute control in CRRT'

Core questions for 'solute control in CRRT'

(1) What is the ideal method to prescribe and measure delivered CRRT dose for solute control?

(2) What are the effects of the delivered dose of CRRT on solute control?

(3) Are different target doses of CRRT needed at various stages of the patient condition?

(4) What quality measures (quality indicators) should monitor dose and solute control in CRRT?

Table 2. Summary of proposed quality measures for CRRT dose

\begin{tabular}{|c|c|c|c|}
\hline Metric & Definition & Calculation & $\begin{array}{l}\text { Benchmark } \\
\text { target }\end{array}$ \\
\hline Dose (clearance) & $\begin{array}{l}\text { This QM focuses on solute clearance to determine delivered dose using } \\
\text { blood and effluent solute concentration. This QM provides an instantaneous } \\
\text { estimate of filter efficacy (i.e., sieving coefficient). This QM can be serially } \\
\text { measured to evaluate solute clearance and filter performance. The default } \\
\text { solute is urea; however, this QM could be applied to additional solutes }\end{array}$ & $\begin{array}{l}\mathrm{QM}=\text { effluent } \\
\text { (urea)/blood (urea) }\end{array}$ & $\geq 0.80$ \\
\hline $\begin{array}{l}\text { Dose } \\
\text { (ratio of delivered/ } \\
\text { prescribed) }\end{array}$ & $\begin{array}{l}\text { This QM focuses on the effluent volume delivered relative to prescribed } \\
\text { dose. This measure would be calculated as the ratio of average effective } \\
\text { delivered dose (time-averaged }(24 \mathrm{~h}) \text { ) divided by prescribed dose }\end{array}$ & $\begin{array}{l}\text { QM = average } \\
\text { effective delivered } \\
\text { dose/prescribed dose }\end{array}$ & $\geq 0.80$ \\
\hline $\begin{array}{l}\text { Effective } \\
\text { treatment time }\end{array}$ & $\begin{array}{l}\text { This QM focuses on the total average time a patient receives treatment in a } \\
\text { given } 24 \mathrm{~h} \text { period. This measure is based on time and would incorporate } \\
\text { treatment interruptions that were planned and unanticipated. Initial } \\
\text { benchmark target should be } \geq 20 \mathrm{~h} / \text { day. Additional QMs related to } \\
\text { contributors and response to unplanned interruptions are necessary } \\
\text { (e.g., catheter function, circuit/filter clotting, anticoagulation) }\end{array}$ & $\begin{array}{l}\mathrm{QM}=24-\text { downtime } \\
\text { (hours) }\end{array}$ & $\geq 20$ \\
\hline $\begin{array}{l}\text { Solute control } \\
\text { indicators }\end{array}$ & $\begin{array}{l}\text { This QM focuses on the absolute and/or relative change in targeted } \\
\text { solutes that represent a target of CRRT prescription }\end{array}$ & $\begin{array}{l}\mathrm{QM}=\text { solute }_{\mathrm{Day}(\mathrm{x}+1)} / \\
\text { solute }_{\mathrm{Day}(\mathrm{x})}\end{array}$ & $\leq 1.0$ \\
\hline $\begin{array}{l}\text { Circuit control } \\
\text { indicators }\end{array}$ & $\begin{array}{l}\text { This QM focuses on temporal trends in circuit and filter membrane } \\
\left.\text { pressures. These would specifically evaluate the pressure drop ( } \mathrm{P}_{\mathrm{DROP}}\right) \\
\text { and transmembrane pressure (TMP). These measures would indicate } \\
\text { suboptimal clearance and risk of treatment interruption }\end{array}$ & $\begin{array}{l}\mathrm{QM}=\text { relative or } \\
\text { absolute changes } \\
\text { in } \mathrm{P}_{\mathrm{DROP}} \text { or } \mathrm{TMP}\end{array}$ & $\begin{array}{l}\mathrm{P}_{\mathrm{DROP}}<? \\
\mathrm{TMP}<?\end{array}$ \\
\hline
\end{tabular}

(e.g., personnel certification, center accreditation, prescription, delivery, anticoagulation, treatment interruptions, catheter-related, circuit-related) [40].

For this ADQI, we have specifically focused on quality measures for CRRT dose prescription, dose delivery and solute control [41, 42]. While proposed quality measures will target discrete aspects of CRRT dose, these should also be complementary. This would imply that no single quality measure can satisfy all the aspects of CRRT dose prescription and delivery (table 2).

We recognize the rapid expansion of electronic medical records, and adaptable bedside clinical informatics has provided opportunity for point-of-care calculation and display of CRRT quality measures. This can be made available to bedside providers caring for the patient (e.g., physicians, nurses). Quality measure data can also be utilized by members of allied health providers (e.g., pharmacists, dieticians) to guide the prescription and adjustment of medications (e.g., antimicrobials) and nutritional support (e.g., calories, protein, micronutrients). This represents an important mechanism to guide precision CRRT prescription, maximize compliance with evidence-informed care and achieve target benchmarks.

We have proposed 4 prototype quality measures to target variable aspects of CRRT dose: delivered clearance, ratio of delivered to prescribed dose, effective treatment time and solute control (table 2). Although CRRT is intended to function $24 \mathrm{~h}$ a day (analogous to a native kidney), treatment is often be interrupted $[15,26]$. It is well established that unplanned interruption of treatment can 
negatively impact CRRT efficiency and safety [15]. We propose that a quality measure should be focused on monitoring 'effective treatment time'. This would further be used to help discriminate whether treatment interruption was planned (e.g., scheduled filter changes, transfers to operating theatre, diagnostic imaging) or rather was unintended (e.g., catheter dysfunction, circuit/filter clotting, anticoagulation; table 2). We contend these quality measures could be reasonably integrated into routine care to guide individual patient CRRT. Moreover, we also contend that these quality measures (and achievement of target benchmarks) should be reported in aggregate at an operational level to facilitate broader quality improvement activities and improvement in CRRT-related operations management.

Quality measures should also be assimilated into larger clinical and/or administrative databases (i.e., data repositories or registries) or a specific CRRT quality registry should be built to further develop, validate and refine quality measures for the purpose of setting benchmark targets for experienced CRRT institutions and those establishing CRRT programs.

\section{Recommendations for Clinical Practice}

All institutions that provide CRRT should integrate, monitor and report quality measures for CRRT. Programs should set target benchmarks for each quality measure. Particular quality measures should be implemented for CRRT dose prescription, delivery and solute control, such as those proposed in table 2, ideally leveraged through bedside EHRs or derived directly from CRRT machine data.

\section{Recommendations for Research}

We identified the following themes for future research focused on quality measures in CRRT:

- Future work should rigorously develop, validate and prioritize specific quality measures for processes of care, treatment-specific end points, patient-centered outcomes and resource utilization for CRRT care.

- Future work should rigorously evaluate target benchmarks for each quality measure that can inform about patient-specific quality of care and aggregate institutional quality of care.

- Future resources should be directed toward developing a multicenter CRRT registry to further develop, validate and refine quality measures for implementation into routine practice and informing on ideal target benchmarks for integration into updated CPG.

\section{Conclusions}

Current CRRT dose is informed from high quality evidence suggesting no impact of static CRRT dose on patient outcomes; however, there is rationale for re-evaluation of CRRT dose to integrate the concept of dynamic solute control adapted to the changing clinical needs of critically ill patients. This concept of dynamic CRRT delivery should target both intended and unintended solute clearance. Quality measures specific for monitoring delivered CRRT dose have been proposed that require further validation prior to implementation into practice to guide optimal CRRT dose.

\section{Acknowledgments}

S.M.B. is supported by a Canada Research Chair in Critical Care Nephrology.

\section{Disclosure Statement}

S.M.B. and A.T. have consulted and received honoraria from Baxter Healthcare Corp.

\section{References}

1 Ronco C, Bellomo R, Homel P, Brendolan A, Dan M, Piccinni P, La Greca G: Effects of different doses in continuous veno-venous haemofiltration on outcomes of acute renal failure: a prospective randomised trial. Lancet 2000;356:26-30.

2 Neri M, Villa G, Garzotto F, Bagshaw SM, Bellomo R, Cerda J, Ferrari F, Guggia S, Joannidis M, Kellum JA, et al: Nomenclature for renal replacement therapy in acute kidney injury: basic principles. Crit Care 2016, in press.
3 Kellum JA, Mehta RL, Angus DC, Palevsky P, Ronco C; ADQI Workgroup: The first international consensus conference on continuous renal replacement therapy. Kidney Int 2002; 62:1855-1863.

4 Kidney Disease: Improving global outcomes (KDIGO) Acute Kidney Injury Work Group: KDIGO clinical practice guideline for acute kidney injury. Kidney Int Suppl 2012;2:1138.
5 Tolwani AJ, Campbell RC, Stofan BS, Lai KR, Oster RA, Wille KM: Standard versus highdose CVVHDF for ICU-related acute renal failure. J Am Soc Nephrol 2008;19:12331238.

6 RENAL Replacement Therapy Study Investigators, Bellomo R, Cass A, Cole L, Finfer S, Gallagher M, Lo S, McArthur C, McGuinness S, Myburgh J, et al: Intensity of continuous renal-replacement therapy in critically ill patients. N Engl J Med 2009;361:1627-1638. 
7 VA/NIH Acute Renal Failure Trial Network, Palevsky PM, Zhang JH, O'Connor TZ, Chertow GM, Crowley ST, Choudhury D, Finkel K, Kellum JA, Paganini E, et al: Intensity of renal support in critically ill patients with acute kidney injury. N Engl J Med 2008;359:7-20.

8 Ronco C, Kellum JA, Bellomo R, Mehta RL: Acute Dialysis Quality Initiative (ADQI). Contrib Nephrol 2013;182:1-4.

9 Ricci Z, Salvatori G, Bonello M, Pisitkun T, Bolgan I, D’Amico G, Dan M, Piccinni P, Ronco C: In vivo validation of the adequacy calculator for continuous renal replacement therapies. Crit Care 2005;9:R266-R273.

10 Huang Z, Letteri JJ, Clark WR, Ronco C, Gao D: Operational characteristics of continuous renal replacement modalities used for critically ill patients with acute kidney injury. Int J Artif Organs 2008;31:525-534.

11 Ricci Z, Ronco C, Bachetoni A, D’Amico G, Rossi S, Alessandri E, Rocco M, Pietropaoli P: Solute removal during continuous renal replacement therapy in critically ill patients: convection versus diffusion. Crit Care 2006; 10:R67.

12 Uchino S, Fealy N, Baldwin I, Morimatsu H, Bellomo R: Pre-dilution vs. post-dilution during continuous veno-venous hemofiltration: impact on filter life and azotemic control. Nephron Clin Pract 2003;94:c94-c98.

13 Yasuda H, Uchino S, Uji M, Ohnuma T, Namba Y, Katayama S, Kawarazaki H, Toki N, Takeda K, Izawa J, et al; Japanese Society for Physicians and Trainees in Intensive Care Clinical Trial Group: The lower limit of intensity to control uremia during continuous renal replacement therapy. Crit Care 2014;18:539.

14 Rewa O, Mottes T, Bagshaw SM: Quality measures for acute kidney injury and continuous renal replacement therapy. Curr Opin Crit Care 2015;21:490-499.

15 Uchino S, Fealy N, Baldwin I, Morimatsu H, Bellomo R: Continuous is not continuous: the incidence and impact of circuit 'down-time' on uraemic control during continuous venovenous haemofiltration. Intensive Care Med 2003;29:575-578.

16 Murugan R, Wen X, Keener C, Pike F, Palevsky PM, Unruh M, Finkel K, Vijayan A, Elder M, Chen YF, et al; Biological Markers of Recovery for the Kidney (BioMaRK) Study Investigators: Associations between intensity of RRT, inflammatory mediators, and outcomes. Clin J Am Soc Nephrol 2015;10:926-933.

17 Fall P, Szerlip HM: Continuous renal replacement therapy: cause and treatment of electrolyte complications. Semin Dial 2010;23:581585.

18 Morimatsu H, Uchino S, Bellomo R, Ronco C: Continuous renal replacement therapy: does technique influence electrolyte and bicarbonate control? Int J Artif Organs 2003;26:289296.
19 Sharma S, Brugnara C, Betensky RA, Waikar SS: Reductions in red blood cell 2,3-diphosphoglycerate concentration during continuous renal replacement therapy. Clin J Am Soc Nephrol 2015;10:74-79.

20 Demirjian S, Teo BW, Guzman JA, Heyka RJ, Paganini EP, Fissell WH, Schold JD, Schreiber MJ: Hypophosphatemia during continuous hemodialysis is associated with prolonged respiratory failure in patients with acute kidney injury. Nephrol Dial Transplant 2011;26: 3508-3514.

21 Honore PM, De Waele E, Jacobs R, Mattens S, Rose T, Joannes-Boyau O, De Regt J, Verfaillie L, Van Gorp V, Boer W, et al: Nutritional and metabolic alterations during continuous renal replacement therapy. Blood Purif 2013; 35:279-284.

22 Wooley JA, Btaiche IF, Good KL: Metabolic and nutritional aspects of acute renal failure in critically ill patients requiring continuous renal replacement therapy. Nutr Clin Pract 2005;20:176-191.

23 Lewis SJ, Mueller BA: Antibiotic dosing in critically ill patients receiving CRRT: underdosing is overprevalent. Semin Dial 2014;27: 441-445.

24 Lewis SJ, Mueller BA: Antibiotic dosing in patients with acute kidney injury: 'enough but not too much'. J Intensive Care Med 2016;31: 164-176.

25 Ricci Z, Romagnoli S, Ronco C: Renal replacement therapy. F1000Res 2016;5:pii:F1000 Faculty Rev-103.

26 Tolwani A: Continuous renal-replacement therapy for acute kidney injury. $\mathrm{N}$ Engl J Med 2012;367:2505-2514.

27 Friedrich JO, Wald R, Bagshaw SM, Burns KE, Adhikari NK: Hemofiltration compared to hemodialysis for acute kidney injury: systematic review and meta-analysis. Crit Care 2012;16:R146.

28 Brunet S, Leblanc M, Geadah D, Parent D, Courteau S, Cardinal J: Diffusive and convective solute clearances during continuous renal replacement therapy at various dialysate and ultrafiltration flow rates. Am J Kidney Dis 1999;34:486-492.

29 Honore PM, Jacobs R, Joannes-Boyau O, De Regt J, De Waele E, van Gorp V, Boer W, Verfaillie L, Spapen HD: Newly designed CRRT membranes for sepsis and SIRS - a pragmatic approach for bedside intensivists summarizing the more recent advances: a systematic structured review. ASAIO J 2013;59:99-106.

30 Maldonado Toral C, Dono L, Parra A, Ramos $\mathrm{N}$, Albertos R, Papiol E, Perez M: Weight gain a risk factor for mortality in patients with acute kidney injury requiring continuous renal replacement therapy. Intensive Care Med Exp 2015;3(suppl 1):A466.

31 Hoste EA, Bagshaw SM, Bellomo R, Cely CM, Colman R, Cruz DN, Edipidis K, Forni LG, Gomersall CD, Govil D, et al: Epidemiology of acute kidney injury in critically ill patients: the multinational AKI-EPI study. Intensive Care Med 2015;41:1411-1423.
32 Srisawat N, Sileanu FE, Murugan R, Bellomod R, Calzavacca P, Cartin-Ceba R, Cruz D, Finn J, Hoste EE, Kashani K, et al; Acute Kidney Injury-6 Study Group: Variation in risk and mortality of acute kidney injury in critically ill patients: a multicenter study. Am J Nephrol 2015;41:81-88.

33 Sharma A, Zaragoza JJ, Villa G, Ribeiro LC, Lu R, Sartori M, Faggiana E, de Cal M, Virzi GM, Corradi V, et al: Optimizing a kidney stress test to evaluate renal functional reserve. Clin Nephrol 2016;86:18-26.

34 Naka T, Bellomo R, Morimatsu H, Rocktaschel J, Wan L, Gow P, Angus P: Acid-base balance in combined severe hepatic and renal failure: a quantitative analysis. Int J Artif Organs 2008;31:288-294.

35 Bellomo R, Ronco C, Kellum JA, Mehta RL, Palevsky P; Acute Dialysis Quality Initiative Workgroup: Acute renal failure - definition, outcome measures, animal models, fluid therapy and information technology needs: the second international consensus conference of the acute dialysis quality initiative (ADQI) group. Crit Care 2004;8:R204-R212.

36 Mehta RL, Kellum JA, Shah SV, Molitoris BA, Ronco C, Warnock DG, Levin A; Acute Kidney Injury Network: Acute kidney injury network: report of an initiative to improve outcomes in acute kidney injury. Crit Care 2007; 11:R31.

37 Ronco C, Bellomo R, Ricci Z: Continuous renal replacement therapy in critically ill patients. Nephrol Dial Transplant 2001;16(suppl 5):67-72.

38 Wald R, McArthur E, Adhikari NK, Bagshaw SM, Burns KE, Garg AX, Harel Z, Kitchlu A, Mazer CD, Nash DM, et al: Changing incidence and outcomes following dialysis-requiring acute kidney injury among critically ill adults: a population-based cohort study. Am J Kidney Dis 2015;65:870-877.

39 Elseviers MM, Lins RL, Van der Niepen P, Hoste E, Malbrain ML, Damas P, Devriendt J; SHARF Investigators: Renal replacement therapy is an independent risk factor for mortality in critically ill patients with acute kidney injury. Crit Care 2010;14:R221.

40 Rewa O, Villeneuve PM, Eurich DT, Stelfox HT, Gibney RT, Hartling L, Featherstone R, Bagshaw SM: Quality indicators in continuous renal replacement therapy (CRRT) care in critically ill patients: protocol for a systematic review. Syst Rev 2015;4:102.

41 Claure-Del Granado R, Macedo E, Chertow GM, Soroko S, Himmelfarb J, Ikizler TA, Paganini EP, Mehta RL: Toward the optimal dose metric in continuous renal replacement therapy. Int J Artif Organs 2012;35:413-424.

42 Lyndon WD, Wille KM, Tolwani AJ: Solute clearance in CRRT: prescribed dose versus actual delivered dose. Nephrol Dial Transplant 2012;27:952-956. 